\title{
Red list of a black box
}

To the Editor - It has recently been announced that for the first time the Federal Agency for Nature Conservation (BfN) Red List (a regional red list of threatened species in Germany) includes groups of soil invertebrates, namely earthworms, millipedes and centipedes ${ }^{1}$. Although these taxa already appear in very small numbers on other regional red lists (http://www.nationalredlist.org/) and the global IUCN Red List (http:// www.iucnredlist.org/), the taxonomic bias towards more charismatic species means that these understudied soil invertebrates are under-represented ${ }^{2}$ (Fig. 1). However, more worrying is the lack of information regarding the threats faced by these species. Of the 47 earthworm species assessed for the BfN Red List based on occurrence data, the most common status was Least Concern (22; although 14 of the 47 earthworm species were assessed as Extremely Rare); however, there are virtually no data on long- or short-term population trends or risks faced ${ }^{1}$. For example, very little is known about the effects of human impacts, such as land-use change and climate change, on below-ground communities ${ }^{3}$, especially compared with above-ground organisms, highlighting the urgent need for more information.

The lack of available soil biodiversity data results in under-representation in many biodiversity databases and synthesis analyses ${ }^{4,5}$. Existing databases often (1) have few data on soil organisms (for example, the PREDICTS database contains just under $1 \%$ of all described annelids ${ }^{6}$, whereas BioTIME ${ }^{4}$ contains no soil invertebrate time-series data); (2) are not global ${ }^{7}$; or (3) concentrate on a small subset of soil taxa ${ }^{8}$. We strongly advocate for data-mobilization initiatives focused on soil biodiversity, in order to address large-scale questions ${ }^{9}$. Such synthetic analyses can be useful in answering key questions as to how soil biodiversity might respond to anthropogenic impacts ${ }^{2,3}$, and if the response differs from those seen in above-ground biodiversity ${ }^{10}$. Given the importance of local biodiversity for ecosystem services and function, determining whether local biodiversity is declining (a hotly debated topic ${ }^{11}$ ), both above- and below-ground ${ }^{2}$, is crucial in sustaining human well-being ${ }^{12}$.

Mobilizing the necessary information and data on the 'black box' of soil

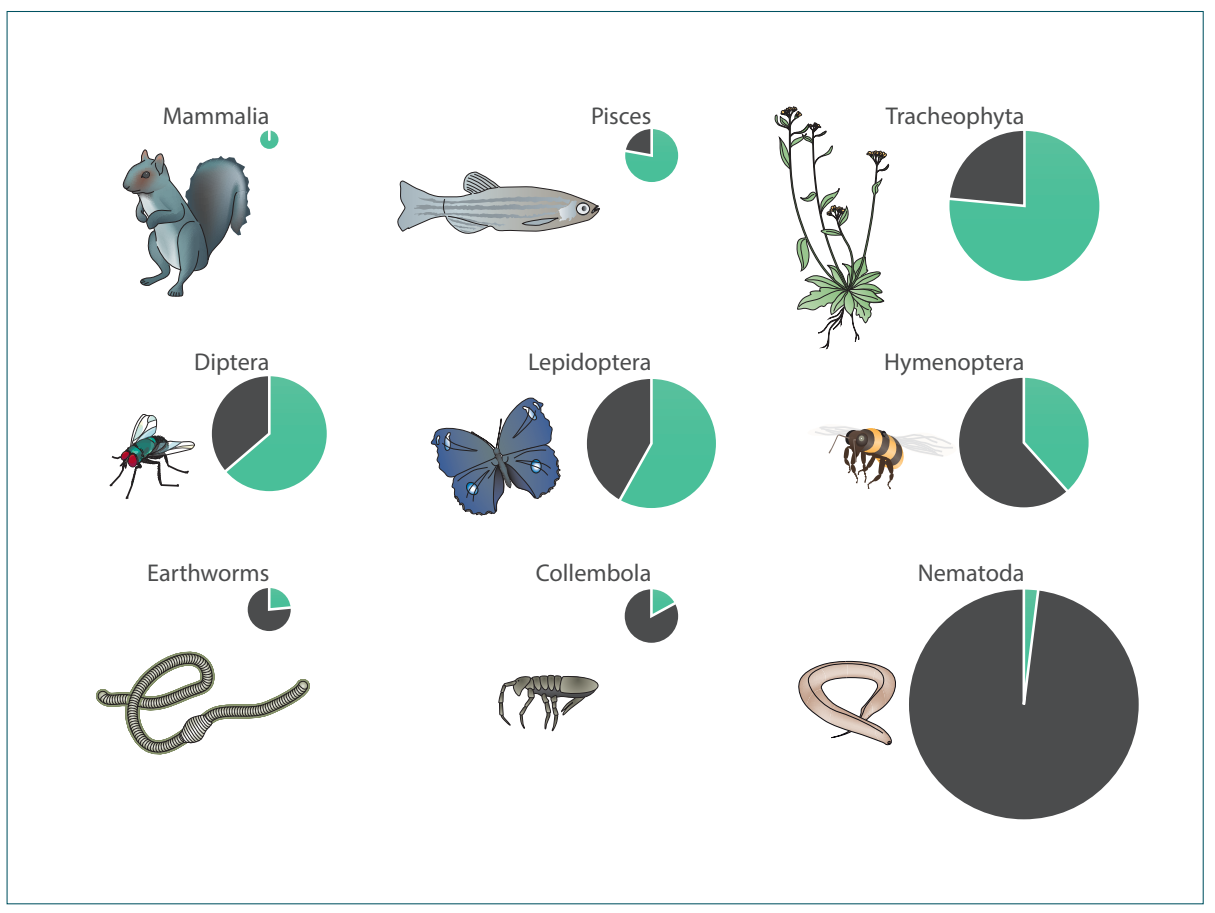

Figure 1 | Proportion of described species (green) and estimated undescribed species (black) for six aboveground taxa (top two rows; estimates from ref. ${ }^{12}$ ) and three below-ground taxa (bottom row; estimates from ref. ${ }^{13}$ ). Size of the individual pie charts is proportional to the total number of estimated species.

biodiversity will require large collaborative initiatives. In addition, increasing the representation of the hidden biota on national and global red lists will help raise the awareness of policymakers as well as the general public, ideally resulting in increased funding for assessments and research in order to better understand changes in this underexplored biodiversity that is so critical for human well-being.

\section{References}

1. Gruttke, H. et al. Rote Liste gefährdeter Tiere, Pflanzen und Pilze Deutschlands. Band 4: Wirbellose Tiere (Teil 2) (2016)

2. Bardgett, R. D. \& Van Der Putten, W. H. Nature 505, 505-511 (2014).

3. Veresoglou, S. D. et al. Nat. Commun. 6, 8862 (2015).

4. Dornelas, M. et al. Science 344, 296-299 (2014).

5. Moran, D. \& Kanemoto, K. Nat. Ecol. Evol. 1, 0023 (2017).

6. Hudson, L. N. et al. Ecol. Evol. 7, 145-188 (2016).

7. Burkhardt, U. et al. Appl. Soil Ecol. 83, 3-12 (2014).

8. Cameron, E. K. et al. Appl. Soil Ecol. 104, 85-90 (2016).

9. Ramirez, K. S. et al. Front. Ecol. Evol. 3, 91 (2015).

10. Gossner, M. M. et al. Nature 540, 266-269 (2016).

11. Gonzalez, A. et al. Ecology 97, 1949-1960 (2016).

12. Wall, D. H. et al. Nature 528, 69-76 (2015).

13. Chapman, A. D. Numbers of Living Species in Australia and the World 2nd edn (Australian Biodiversity Information Services, 2009).

14. Orgiazzi, A. et al. Global Soil Biodiversity Atlas (European Commission, Publications Office of the European Union, 2016).
Acknowledgements

We thank T. Arnhold for initiating the discussion on soil invertebrates in red lists and acknowledge support by the German Centre for Integrative Biodiversity Research (iDiv) Halle-Jena-Leipzig (funded by the German Research Foundation, FZT 118), the European Research Council (ERC Starting Grant 677232, ECOWORM), and the Academy of Finland (285882).

Competing interests

The authors declare no competing financial interests.

Helen R. P. Phillips ${ }^{1 \star}$, Erin K. Cameron ${ }^{2,3}$, Olga Ferlian ${ }^{1,4}$, Manfred Türke ${ }^{1,4}$, Marten Winter ${ }^{1}$ and Nico Eisenhauer ${ }^{1,4}$ ${ }^{1}$ German Centre for Integrative Biodiversity Research (iDiv) Halle-Jena-Leipzig, Deutscher Platz 5e, 04103 Leipzig, Germany. ${ }^{2}$ Metapopulation Research Centre, Department of Biosciences, University of Helsinki, PO Box 65, 00014 Helsinki, Finland. ${ }^{3}$ Center for Macroecology, Evolution and Climate Change, Natural History Museum of Denmark, University of Copenhagen, Universitetsparken 15, København, DK2100 Denmark. ${ }^{4}$ Institute of Biology, Leipzig University, 04103 Leipzig, Germany. *e-mail: helen.phillips@idiv.de 